\title{
Problems of the socially disadvantaged child in Colombo: a pilot project
}

\author{
M P Senanayake ${ }^{1}$, S P Lamabadusuriya ${ }^{2}$, T Seneviratne $^{3}$
}

Sri Lanka Journal of Child Health, 2000; 29: 109-11

(Key words: Socially disadvantaged child, Sri Lanka)

\begin{abstract}
Data on the disadvantaged urban child is meagre. A prospective survey of 60 households in Borella North, each with at least one child under 2 years of age, was carried out over 8 months. The socioeconomic status, the physical environment and the health of the population were investigated.
\end{abstract}

One hundred and ten families lived in the 60 households and $29 \%$ of the population were under the age of 5 years. Only a minority of families had regular employment. The source of water was the roadside tap for $70 \%$ of households. Solid waste and blocked drains were present in the environment. $80 \%$ of homes were over-crowded. Family planning was practised only by $17 \%$ of parents. $25 \%$ of under fives were in grade 2 protein calorie malnutrition and $20 \%$ of this age group needed at least one hospital admission during the study period.

We conclude that the disadvantaged urban child has health risks that need multidisciplinary interventions.

\section{Introduction}

Urbanisation has become a world-wide phenomenon with an increasing proportion of the world population living in urban areas. Cities in Latin America, Africa and Asia have the highest growth rates and rapid urbanisation is associated with several health related problems.

Colombo is a city with a population of over two million and has a growth rate of $1.14 \%$ per annum ${ }^{1}$.

Inadequate space and high cost of accommodation have resulted in mushrooming of squatter settlements in many parts of Colombo. It is estimated that $50 \%$ of Colombo's population live in temporary dwellings. Faced with living conditions where shelter, water,

${ }^{1}$ Senior Lecturer in Paediatrics, ${ }^{2}$ Senior Professor in Paediatrics, University of Colombo. ${ }^{3}$ Chief Medical Officer, Colombo Muncipal Council sanitation, overcrowding and pollution ${ }^{2,3}$ are problems, it is the child who suffers the most.

\section{Objective}

To study the health and health related problems of the socially disadvantaged child in Colombo.

\section{Study Design}

A cross-sectional prospective observational study.

\section{Method}

A prospective survey of 60 households was carried out in Borella North during 1995-96 over a period of 8 months. This area was selected due to its proximity to the Children's Hospital and the Faculty of Medicine. The households were randomly selected from those with a child aged below 2 years. The socioeconomic status, the using a structured questionnaire. Field visits by a multidisciplinary group of research workers, i.e. medical officer physical environment and the health of children in the study population were investigated. The microenvironment, i.e. those conditions that prevail at the level of the individual households, as well as the macroenvironment, i.e. the influences outside the households, were both studied. In depth interviews were carried out by a social worker of health, health warden, family health worker, public health inspector and academic staff of the Departments of Paediatrics and Community Medicine, University of Colombo were conducted weekly.

\section{Results}

One hundred and ten families lived in the 60 households surveyed and formed a total population of 366 persons. Males and females showed an equal distribution. $29 \%$ of the population were under the age of 5 years (Figure 1). The family structures were nuclear in $60 \% .5 \%$ of the mothers were employed abroad. 
The main economic provider was the father. $69 \%$ were employed on a temporary (daily) basis, $26 \%$ had regular employment and $4 \%$ of the families had an income from abroad.

The majority earned a monthly income of Rs.2000/= to $4000 /=$ per month as three wheeler drivers, street vendors and unskilled labourers. $17.5 \%$ earned less than Rs.2000/= per month. The literacy rate for adult females was $70 \%$ and adult males $90 \%$.

Overcrowding defined as $<360 \mathrm{ft}^{3}{ }^{3} />10 \mathrm{yr}$. olds and $<180 \mathrm{ft}^{3} /<10$ yr. olds was present in $19 \%$ of the households. The 60 houses were constructed with walls of wooden planks in $22 \%$, bricks in $78 \%$, asbestos roofs in $42 \%$, tin roofs in $36 \%$ and tiled roofs in $22 \%$ while illumination was by electricity in $65 \%$ and kerosene oil lamps in $35 \%$.

The entire population used pipe borne water. $70 \%$ of the households depended on roadside taps situated among squalid mounds of domestic waste while $30 \%$ had supplies of pipe borne water into their homes. Only $29 \%$ of the population had indoor toilet facilities. $65 \%$ used common "public toilets" all of which were in a state of disrepair. $6 \%$ shared the use of toilets with neighbouring houses.

Disposal of solid waste was irregular due to the approach roads being too narrow for the garbage collecting vehicles. Blocked drains overflowing with sewerage ran adjacent to some of these households.

During a period of follow up of 8 months, 14 (20\%) of the under fives had at least one hospital admission.
These were for acute respiratory tract infections [7], diarrhoea [3], fever [2], rash [1] and injuries [1].

The nutritional assessment of the under five age group showed PCM I in 25\% and PCM 11 in 25\% PCM 111 was not seen.

$62 \%$ of the families had one or two children, $27.7 \%$ had three children while $5.5 \%$ had four or more. Contraceptives were used by only $16.6 \%$ of parents at the time of the survey. Injectable hormonal contraceptives, used by $44 \%$, was the most popular method. The teaching hospitals in the vicinity were utilised more than the health centre for immunisation and family planning services.

Prevalence of crime was high, the details of which could not be accurately assessed. Encounters with law enforcement authorities by the parents during this period of 8 months were imprisonment [2], drug related offences [31 and alcohol related offences [9].

Education facilities were being availed of by school age children with only 2 not schooling due to lack of birth certificates. This was rectified.

\section{Discussion}

Data on the disadvantaged urban child of Sri Lanka is meagre and often diluted by peers who enjoy good living conditions. Further it is the general belief that urban populations are healthier and need less health promotion than rural populations.

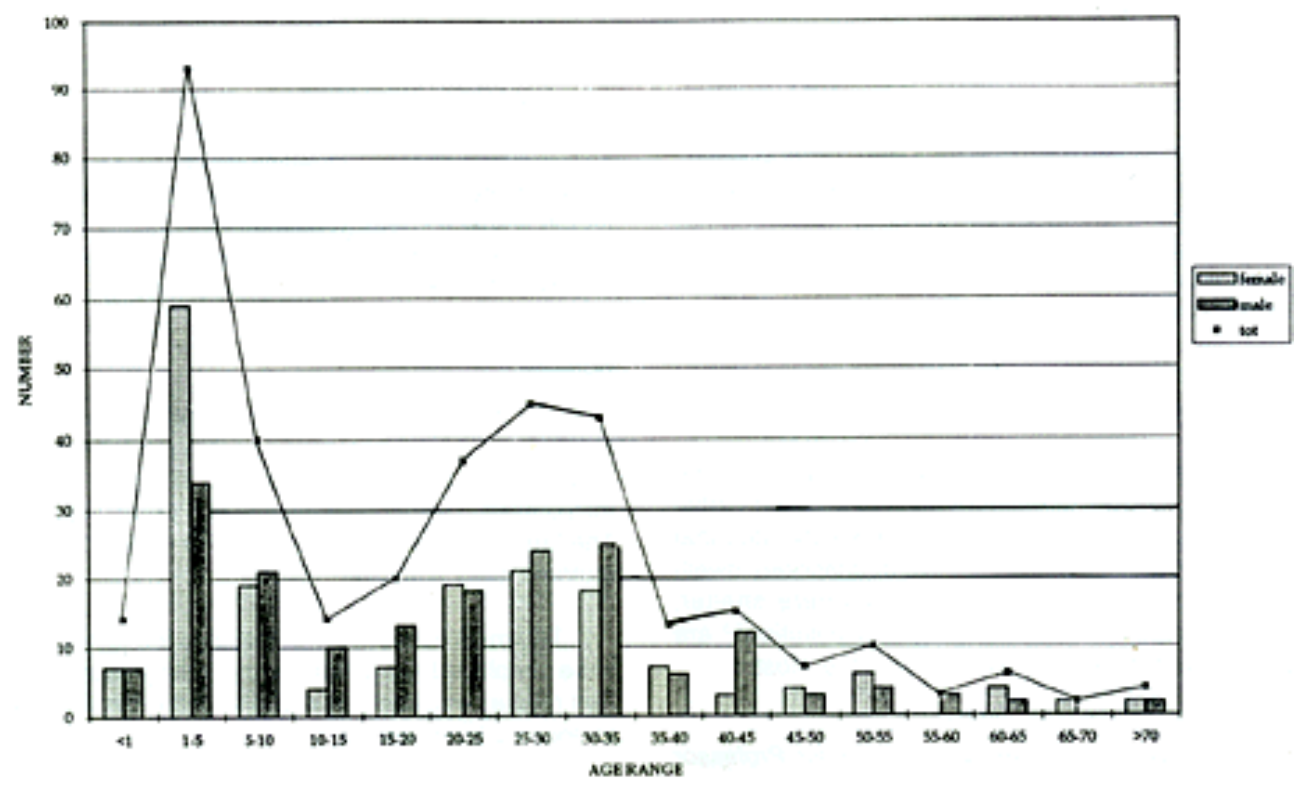

Figure 1. Population Structure 
We found the urban poor live in environments detrimental to their health with uncollected rubbish, blocked drains, stagnant water in puddles and receptacles, inadequate sanitation and overcrowded living conditions.

In this survey children under the age of 5 years comprised almost one third of the population. Acute infections were common with a high hospital admission rate for young children.

Among disadvantaged families living in the heart of the city, kerosene oil remained an important source of lighting. Family planning acceptance was low.

Although there was a high rate of crime among adults there was no child abuse detected. The family health worker served a population of 22,000 although the stipulated number was 3000 .

We recommend that the problems of the disadvantaged urban child be addressed by the authorities, if the city and its children are to function and grow productively.

The study team also comprised Prof D. Femando, Dr L.C. Rajapaksa, Dr R. Seneviratne and Dr W. Gunathunga of the Department of Community Medicine, Dr K.S.H. de Silva, Dr U.D.Mahamithawa, Dr R. Ajanthan and Dr G. D. I. de Silva of the
Department of Paediatrics, Dr S. Jayawickrama of the Colombo Municipal Council and Dr H. Wijemanne of UNICEF, Colombo.

\section{References}

1. Building a Healthy City: A practitioners guide (WHO) publication. $1996 \mathrm{WHO} / \mathrm{ESO} / 95.10$ 1-4.

2. Report on Community Development Council Formulation 1999: Colombo Municipal Council (personal communication).

3. WHO Healthy Cities; a programme framework 1995. WHO/ ESO/95. 11.

4. Senanayake M P, Amarathunga S, Hubert H D M, Sumanasena S P, Jayawickrama D T A. Is Colombo choking its children? Proceedings of the Sri Lanka College of Pediatricians Annual Scientific Congress, 1999; 1 (3): 53-4.

5. Senanayake M P, Sumanasena S P, Hubert H D $\mathrm{M}$, Amarathunga S. Is lead exposure affecting rieuro development of urban children in Sri Lanka ? Proceedings of the Sri Lanka College of Paediatricians Annual Scientific Congress, 2000; 2 (1): 47-8. 